\title{
Reflets
}

Revue ontaroise d'intervention sociale et communautaire

\section{Les services à la jeunesse de Hearst}

\section{Lyne Poliquin}

Volume 1, numéro 1, printemps 1995

Des pratiques à notre image : défis et ressources

URI : https://id.erudit.org/iderudit/026066ar

DOI : https://doi.org/10.7202/026066ar

Aller au sommaire du numéro

Éditeur(s)

Reflets : Revue ontaroise d'intervention sociale et communautaire

ISSN

1203-4576 (imprimé)

1712-8498 (numérique)

Découvrir la revue

Citer cet article

Poliquin, L. (1995). Les services à la jeunesse de Hearst. Reflets, 1(1), 216-218.

https://doi.org/10.7202/026066ar

Tous droits réservés (C) Reflets : Revue ontaroise d'intervention sociale et communautaire, 1995

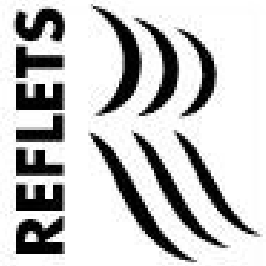

Ce document est protégé par la loi sur le droit d'auteur. L'utilisation des services d'Érudit (y compris la reproduction) est assujettie à sa politique d'utilisation que vous pouvez consulter en ligne.

https://apropos.erudit.org/fr/usagers/politique-dutilisation/ 


\title{
Les services à la jeunesse de Hearst
}

\author{
Lyne Poliquin \\ Professeure, Collège universitaire de Hearst
}

En 1979, des gens de Hearst, préoccupés par les difficultés rencontrées par la jeunesse, développent un projet, auquel on donne le nom La Source, et dont l'objectif est d'offrir aux enfants et aux adolescents et adolescentes de la région un service de prévention primaire dans le but de réduire les risques liés à la délinquance. Le 20 mars 1984, le ministère des Services sociaux et communautaires confere un statut permanent à l'organisme La Source qui, depuis 1982, s'est incorporé sous le nom de Services à la Jeunesse de Hearst (SAJ). Pour la première fois dans son histoire, l'organisme de prévention primaire pouvait donc, dans sa programmation, se donner des objectifs à long terme. Les SAJ offrent maintenant un programme avec deux volets bien distincts, dont un de formation et l'autre de prévention.

Voici un bref apercu de ces programmes.

\section{Des projets de formation}

En 1983, le programme de formation a mis sur pied une coopérative Jeunesse au travail. Ce programme offre des ateliers portant sur des questions telles que le fonctionnement d'une coopérative, le leadership, les cours de gardiennage et la connaissance de soi, favorisant ainsi chez les participantes et participants une prise de conscience de leurs forces et de leurs faiblesses, de même que le développement de leurs habiletés et d'une meilleure confiance en eux. Forts de ces acquis, les jeunes sont davantage motivés à poursuivre leurs études, ce qui leur permet d'échapper aux problèmes d'analphabétisation très présents dans le Nord 
ontarien. Ces ateliers sont offerts dans un endroit conçu expressément pour eux, soit la Maison des Jeunes.

La Maison des Jeunes a été créée en 1985, afin que les jeunes aient un lieu où ils se sentent libres d'exprimer leurs besoins et leur créativité, tout en organisant des activités susceptibles de les éloigner du monde de la délinquance. Un exemple du positif de ces activités fut la formation par les jeunes de leur propre conseil d'administration (lequel, soit dit en passant, est composé de six membres). On retrouve là une démonstration de la volonté des jeunes de se prendre en main, lorsque certaines structures de base sont mises à leur disposition. Jusqu'à maintenant, à chaque année, plus de mille jeunes bénéficient des programmes offerts à la Maison des Jeunes.

\section{Des idées de prévention}

Afin d'assurer une meilleure coordination des services de prévention offerts aux jeunes, le programme de prévention des SAJ a mis sur pied un comité (Comité de prévention) regroupant les différentes agences de Hearst engagées de près ou de loin auprès de la jeunesse. Les SAJ ont pour fonction de coordonner les activités de prévention proposées par ce comité. Ainsi, dans le cadre du programme de prévention réalisé conjointement avec les écoles primaires et secondaires, des activités éducatives ont été organisées. Celles-ci prenaient la forme de sketches et de discussions sur divers thèmes, tels les méfaits de la consommation de la drogue et de l'alcool, le suicide, la jalousie, l'estime de soi, la pression des pairs, etc. De l'avis du personnel enseignant et des élèves, ces rencontres ont été couronnées d'un franc succès.

En 1982, toujours dans une optique de prévention et de formation, les SAJ ont développé le programme Source deVie (camp d'été). Ce programme offre aux jeunes la possibilité de découvrir leur potentiel et de prendre conscience de leurs capacités et cela, par l'intermédiaire d'activités développées dans le cadre d'un camp d'été. Le camp accueille maintenant plus de cent jeunes par été. 
Reflets

De plus, depuis 1992, le responsable du volet prévention, M. Pierre Fontaine, coordonne le programme BABES à la garderie Bouts de chou de Hearst et au Rendez-vous familial. Le programme BABES a été conçu dans le but de renseigner les enfants sur les effets néfastes de l'abus des drogues et de l'alcool. Cette année, M. Fontaine travaille de concert avec le Conseil des écoles séparées et le Centre de garde afin d'implanter le programme BABES dans le système scolaire.

Finalement, depuis 1993, les SAJ jouissent d'un appui supplémentaire, soit un comité de parents agissant en tant que conseiller. Ce comité offre des suggestions aux SAJ pour améliorer leur programmation afin que celle-ci réponde le plus efficacement possible aux besoins des enfants et des jeunes.

\section{Conclusion}

D'autres communautés du Nord, soit Dubreuilville, Longlac et Kapuskasing, aux prises avec les mêmes réalités socio-économiques, ont communiqué avec les SAJ de Hearst pour discuter de la mise sur pied d'un programme de prévention primaire qui puisse aussi répondre aux difficultés que rencontrent leurs jeunes. Il est à noter que Longlac a ouvert, cette année, sa Maison des Jeunes.

Les SAJ favorisent chez les jeunes Franco-Ontariens et FrancoOntariennes de notre région un sain développement socioaffectif. La communauté de Hearst, en général, appuie moralement et financièrement les SAJ. Cet appui souligne la confiance que s'est méritée l'organisme auprès de la population au fil des ans.

Pour de plus amples informations concernant les SAJ, on peut communiquer avec:

- Michèle LeBlanc, directrice

- Pierre Fontaine, responsable du volet prévention ou

- Tammy Larouche, responsable du volet formation au numéro suivant: (705) 362-7427. 